\title{
Pseudoaneurysm of the facial artery occurred after mandibular sagittal split ramus osteotomy
}

\author{
H.-W. Jo • Y.-S. Kim • D.-H. Kang • S.-H. Lee • T.-G. Kwon
}

Received: 4 April 2012 / Accepted: 16 July 2012 /Published online: 2 August 2012

(C) Springer-Verlag 2012

\begin{abstract}
Introduction Pseudoaneurysms are caused by rupture of arteries with extravasation of blood. The compressed perivascular tissue forms the wall of aneurysmal sac. Pseudoaneurysm directly related with surgical procedure of sagittal split ramus osteotomy (SSRO) was reported quite rarely especially related with facial artery during the vertical osteotomy.

Case report SSRO was carried out for a 19-year-old male; the patient visited the emergency room with notable swelling 3 weeks after the surgery. We experienced severe intra-oral bleeding with surgical exploration. Angiography revealed a pseudoaneurysm of the right facial artery that might be related with vertical osteotomy over lateral cortex of the mandibular body during orthognathic surgery. This implies that the minor vascular trauma from vertical osteotomy of the mandibular body during the conventional orthognathic surgery might cause later development of pseudoaneurysm.
\end{abstract}

Keywords Pseudoaneurysm · Sagittal split ramus osteotomy $\cdot$ Angiography

H.-W. Jo • S.-H. Lee $・$ T.-G. Kwon $(\bowtie)$

Department of Oral and Maxillofacial Surgery,

School of Dentistry, Kyungpook National University,

Samduck $2 \mathrm{Ga}$, Jung Gu,

Daegu 700-421, South Korea

e-mail: taegeonkwon@gmail.com

Y.-S. Kim • D.-H. Kang

Department of Radiology, School of Medicine,

Kyungpook National University,

Samduck $2 \mathrm{Ga}$, Jung Gu,

Daegu 700-421, South Korea

\section{Introduction}

Pseudoaneurysm (or false aneurysm) is typically caused by the rupture of arteries with extravasation of blood. The compressed perivascular tissue forms the wall of the aneurysmal sac and develops to the mass with active pulsation. Pseudoaneurysm differ from true aneurysm in that the latter involves abnormal expansion of the arteries due to the weakening of the vessel walls and blood accumulates between the layer of arterial wall [1].

Pseudoaneurysm occurs rarely after orthognathic surgery or other surgical procedures in the head and neck area. The previously reported cases of pseudoaneurysm most frequently occurred in the maxillary artery related with Le Fort I osteotomy [2]. However, only two cases of pseudoaneurysm directly related with of sagittal split ramus osteotomy (SSRO) was reported; maxillary artery injury during the medial osteotomy [3], facial artery injury due to drain placement [4]. As the facial artery lies ascends from submandibular gland and winds around inferior border of the mandible, there is possibility of damage of this vessel during the vertical osteotomy of SSRO. However, to our knowledge, no other reports show such an incidence. We present a case of pseudoaneurysm of facial artery that might be related with vertical osteotomy over lateral cortex of the mandibular body during SSRO.

\section{Report of a case}

A 19-year-old male patient visited the Department of Oral and Maxillofacial Surgery of the authors' hospital for treatment of skeletal class III deformity. The patient had undergone orthodontic treatment for 2 years before the orthognathic surgery. The patient was obese (height, $174 \mathrm{~cm}$; weight, $95 \mathrm{~kg}$ ), but did 
not have systemic disease. There was no abnormal finding in presurgical laboratory results, ECG, and chest radiograph. A bilateral sagittal split ramus osteotomy was successfully performed intraorally. Although there was minor bleeding at the inferior border of the mandible, bleeding was controlled successfully simply by temporary packing; there had been no excessive bleeding during the surgery. The postoperative healing process was uneventful. However, after 3 weeks of operation, the patient complained of pain with swelling on his right cheek. In the intraoral examination, a small dehiscence was observed in the right retromolar area and blood was gradually oozing out from the dehiscence area, accompanied by a slight foul odor. Based on such findings, the patient was diagnosed with buccal space abscess and incision and drainage were performed superficially via vestibular approach; there had been no excessive bleeding at the time. After 3 days, the patient visited the hospital's emergency room because of the severe bleeding and swelling on his right cheek. The CT image showed the radiopaque region within the radiolucent cavity inside of the well-circumscribed right buccal space (Fig. 1). Laboratory result showed hemoglobin of $9.10 \mathrm{~g} / \mathrm{dL}$ and hematocrit of $25.4 \%$; blood loss was suspected. To control the bleeding, a gauze was inserted and pressure was
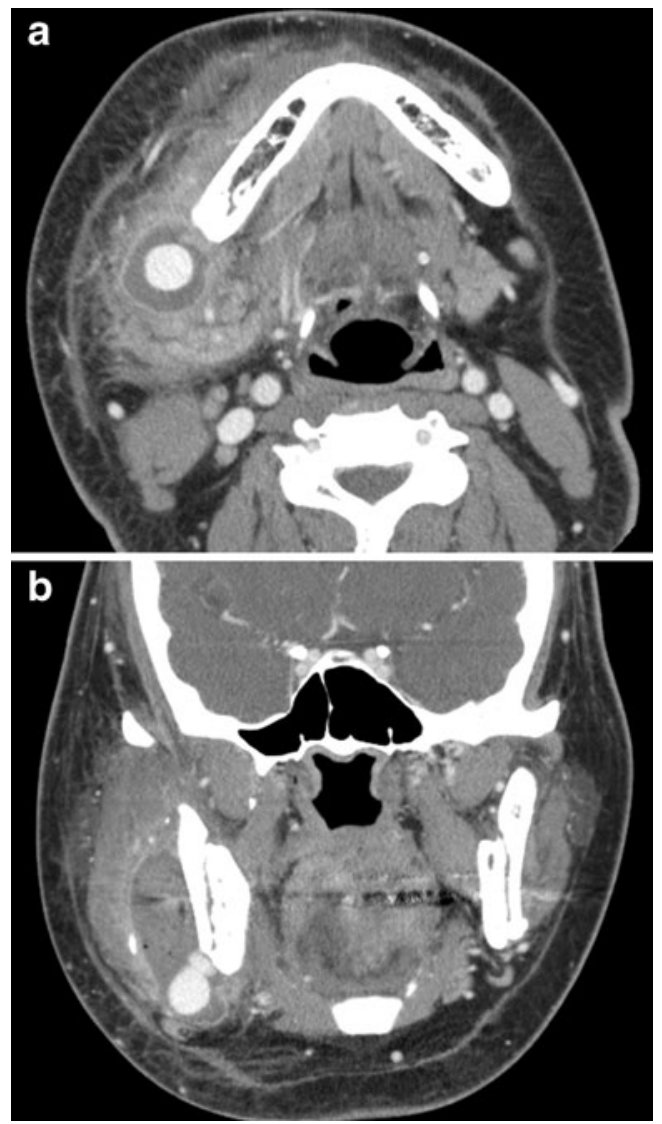

Fig. 1 Computerized tomography (CT) enhanced with intravenous contrast: a axial view, b coronal view revealed a radiopaque pseudoaneurysm near to the right inferior border of the mandible applied from outside. The bleeding gradually diminished and stopped completely after Surgicel ${ }^{\circledR}$ (Ethicon, NJ, USA) was applied. As the patient complained of slight weakness and dizziness due to excessive bleeding, lab test was immediately carried out; it showed that the patient's hemoglobin was $7.70 \mathrm{~g} / \mathrm{dL}$ and hematocrit was $21.3 \%$, which were significantly lower than normal. The patient was given a blood transfusion with packed red cells $\left(400 \mathrm{~cm}^{3}\right)$. The next morning, however, bleeding occurred again at the same area. To temporarily control the bleeding, a gauze was inserted again in the bleeding area, pressure dressing was applied from outside, and angiography was performed. The angiography via right femoral artery revealed pseudoaneurysm of the patient's right facial artery (Fig. 2a). Endovascular embolization was immediately performed using $N$-butyl-2-cyanoacrylate (Histoacryl ${ }^{\circledR}$; Fig. 2b).

On the next day, angiographic examination was performed again and confirmed that the pseudoaneurysm had completely disappeared (Fig. 3) and the patient no longer complained of any discomfort. The patient was discharged from the hospital. Eighteen months later, at present, the wound shows favorable healing without any recurrence of vascular malformation.
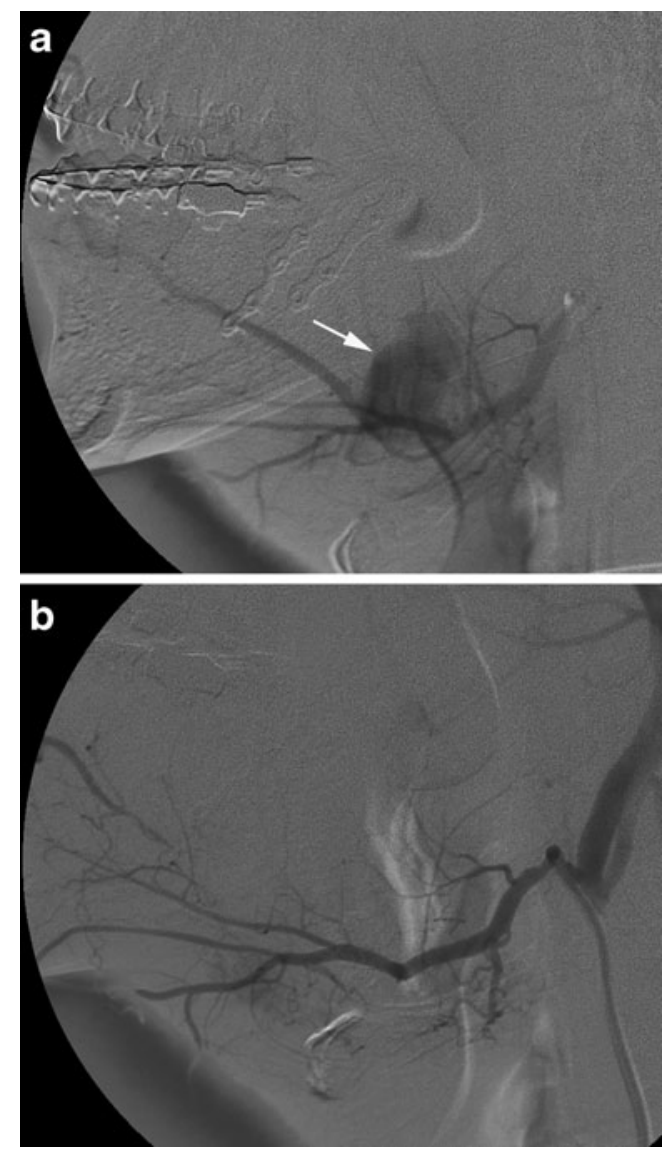

Fig. 2 Angiographic embolization of pseudoaneurysm. a Prepoerative angiogram revealed a pseudoaneurysm of the right facial artery (white arrow). b Post-embolization angiogram shows resolution of aneurysm 

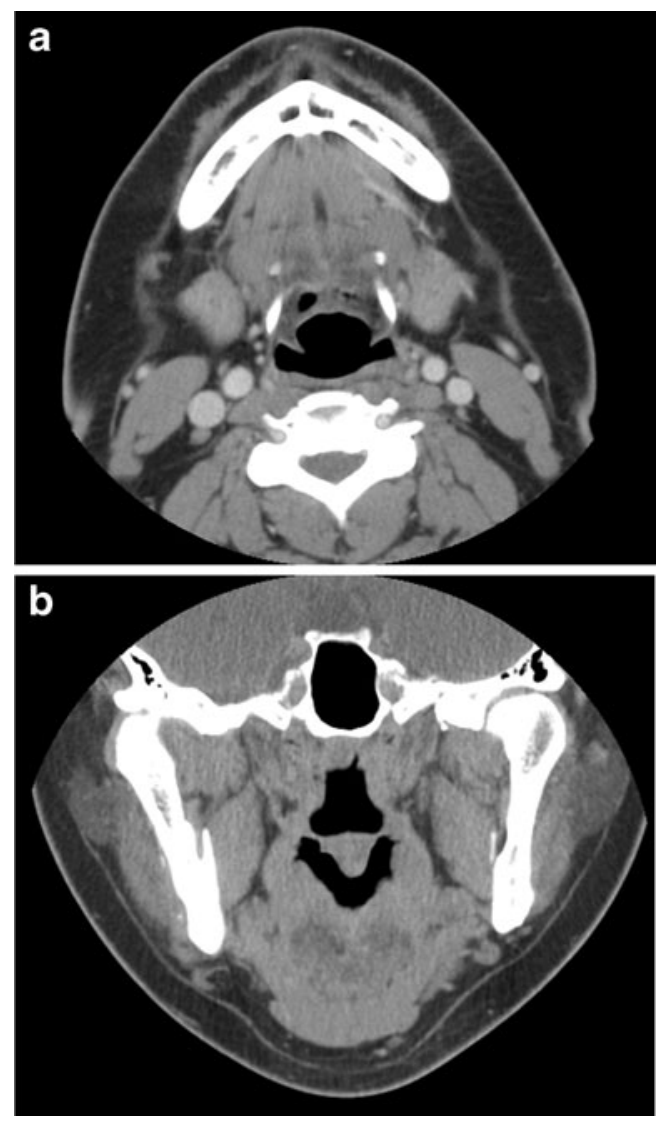

Fig. 3 Postoperative follow-up CT shows no further complication after the embolization; a axial view, b coronal view

\section{Discussion}

Pseudoaneurysm in the facial area is very rare, and it normally occurs due to surgical procedures in the maxillofacial trauma [5], dental extraction [6, 7], or orthoganthic surgery $[3,4,8]$. According to literature review, cases in which pseudoaneurysm occurred after orthognathic surgery are extremely rare, with only 15 cases reported [2-4, 8-19]. Out of these 15 cases, 10 cases involved pseudoaneurysm after Le Fort I osteotomy; two cases involved pseudoaneurysm after mandibular vertical subcondylar osteotomy [10, 18] and only three cases involved pseudoaneurysm after SSRO $[3,4,8]$. In the case of Le Fort I osteotomy, all the pseudoaneurysms occurred in the maxillary artery or its branches. In the case of the mandibular vertical subcondylar osteotomy, the location of the pseudoaneurysm was not accurately specified, but it is highly likely to have been at the maxillary artery position. In the case of the SSRO, one case occurred in the maxillary artery [3] and two cases were related with facial artery $[4,8]$. There is a possibility of damage to the maxillary artery when medial ramus cutting is performed around the sigmoid notch, that is, the upper part of the ascending branch [12]. Also, when the direction of the medial cutting is sloped towards the cranial region, the sharp distal end bony spike can irritate the maxillary artery walls [20]. Actually, pseudoaneurysm in the maxillary artery after performing SSRO was reported and attributed to inappropriate location of the medial cutting [3]. Recently, pseudoaneurysms in the facial artery after SSRO have been reported. Papa et al. [4] suggested its cause as the damage to the facial artery by the drain inserted in the operation wound. Mandani et al. [8] reported that pseudoaneurysm occurred due to postoperative facial trauma after the SSRO but difficult to know whether it is directly related to the SSRO surgical procedure itself. The difference in our case, however, is that there seems to have been no damage to the facial artery with the application of an intraoral drain after the surgery, and no trauma was applied to the operation wound after the surgery. Judging from this, it seems that the facial artery was damaged because there was no sufficient soft tissue traction and protection of the inferior boundary of the mandible upon the vertical osteotomy during the surgery. In reality, because the inferior border of the mandible and the facial artery are very close to each other, if the soft tissue is not protected by sufficient dissection and traction upon surgery, there might be significant damage to the blood vessels. To prevent such a complication, sufficient dissection and traction upon surgery are needed, and the area that is expected to have a trauma must be protected with the use of an instrument. In addition, the operation should be performed based on sufficient understanding of the possible pathogenesis of pseudoaneurysm.

Pseudoaneurysm is caused by partial rupture of arteries. The extravasations of blood from the cut area forms an aneurysmal sac composed of the nearby connective tissues, and the bleeding continues until the hematoma and arterial pressure become the same. Once the center of the hematoma liquefies, the aneurysmal sac and the artery communicate to form a pulsatile mass. Then, as the pseudoaneurysm gradually expands due to the arterial pressure, it continues to enlarge or ruptures [3]. The growth of such pseudoaneurysm may sometimes be delayed by several weeks to several years. In the case in this paper, pseudoaneurysm developed about 3 weeks after surgery. Furthermore, during the initial stage of the trauma, pseudoaneurysm is difficult to diagnose because it has no particular symptoms. If left untreated, however, it may cause complications such as excessive bleeding due to rupture [4], pressures on nearby tissues, and paralysis due to the growth of the pseudoaneurysm [21]. Pseudoaneurysm can be treated by ligating the blood vessel, which is the cause of the lesion, and then can be possibly removed surgically. However, the surgical remove of pseudoaneurysm has fundamental limitations such as external scar formation or excessive bleeding during the surgical exploration. For this reason, the treatment of pseudoaneurysm using angiography and endovascular embolization is being introduced with favorable results. Such treatment is less invasive and more elective than traditional surgical 
techniques, and is useful for the treatment of pseudoaneurysm in areas that are difficult to access surgically. Moreover, it reduces the risk of bleeding and revascularization of the pseudoaneurysm via collateral circulation. Furthermore, the treatment effect can be checked immediately through angiography after embolization, and this has an advantage in that it can shorten the duration of hospitalization and is costeffective. Although angiographic embolization is quite reliable and safe method, neurological complication or soft tissue necrosis related with destruction of existing vascular lesion or reflux of embolization material had been reported [22, 23]. The last option of treating the pseudoaneurysm is the surgical exploration and the removal of the lesion, especially when the lesion is located superficially and directly accessible [3] or the excessive radiation exposure is discouraged in growing children [24]. Therefore, we suggest pathway of the management for pseudoaneurysm as follows; interventional radiology as the first-line treatment and surgical approach as secondary option especially for the aforementioned indications.

In this case, although the postoperative progress was uneventful, patient experienced the excessive bleeding 3 weeks after the surgery. This implies that the minor vascular trauma from vertical osteotomy of the mandibular body during the conventional orthognathic surgery might cause later development of pseudoaneurysm. Early diagnosis and immediate angiographic embolization would minimize the patient's complication.

\section{References}

1. Galindo CC, Lima CA, Filho G, Penha MF (2006) True atherosclerotic aneurysm of the facial artery. Int J Oral Maxillofac Surg 35:566-568

2. Avelar RL, Goelzer JG, Becker OE, de Oliveira RB, Raupp EF, de Magalhãe PS et al (2010) Embolization of pseudoaneurysm of the internal maxillary artery after orthognathic surgery. J Craniofac Surg 21:1764-1768

3. Silva AC, O'Ryan F, Beckley ML, Young HY, Poor D (2007) Pseudoaneurysm of a branch of the maxillary artery following mandibular sagittal split ramus osteotomy: case report and review of the literature. J Oral Maxillofac Surg 65:1807-1816

4. Pappa H, Richardson D, Niven S (2008) False aneurysm of the facial artery as complication of sagittal split osteotomy. J Cranio Maxillo Fac Surg 36:180-182

5. Orihovac Z, Virag M, Manojlovic S (1999) Traumatic facial artery aneurysm: case report. J Oral Maxillofac Surg 57:199-201

6. Rayati F, Parsa H, Abed PF, Karagah T (2010) Facial artery pseudoaneurysm following surgical removal of a mandibular molar. J Oral Maxillofac Surg 68:1683-1685
7. Marco de Lucas E, Gutiérrez A, González Mandly A, García-Pire F, Marco de Lucas MT, Parra JA, Sáiz-Bustillo R (2008) Lifethreatening pseudoaneurysm of the facial artery after dental extraction: successful treatment with emergent endovascular embolization. Oral Surg Oral Med Oral Pathol Oral Radiol Endod 106:129-132

8. Madani M, Veznedaroglu E, Pazoki A, Danesh J, Matson SL (2010) Pseudoaneurysm of the facial artery as a late complication of bilateral sagittal split osteotomy and facial trauma. Oral Surg Oral Med Oral Pathol Oral Radiol Endod 110:579-584

9. Hemmig SB, Johnson RS, Ferraro N (1987) Management of a ruptured pseudoaneurysm of the sphenopalatine artery following a Le Fort I osteotomy. J Oral Maxillofac Surg 45:533-536

10. Clark R, Lew D, Giyanani VL, Gerlock A (1987) False aneurysm complicating orthognathic surgery. J Oral Maxillofac Surg 45:57-59

11. Solomons NB, Blumgart R (1988) Severe late-onset epistaxis following Le Fort I osteotomy: angiographic localization and embolization. J Laryngol Otol 102:260-263

12. Lanigan DT, Hey JV, West RA (1991) Major vascular complications of orthognathic surgery: false aneurysms and arteriovenous fistulas following orthognathic surgery. J Oral Maxillofac Surg 49:571-577

13. Lustbader DP, Schwartz MH, Zito J, Stern M (1991) The use of percutaneous transcatheter embolization to control postoperative bleeding following Le Fort I osteotomy: report of three cases. J Oral Maxillofac Surg 49:426-431

14. Bradley JP, Elahi M, Kawamoto HK (2002) Delayed presentation of pseudoaneurysm after Le Fort I osteotomy. J Craniofac Surg 13:746-750

15. Procopio O, Fusetti S, Liessi G, Ferronato G (2003) False aneurysm of the sphenopalatine artery after a Le Fort I osteotomy: report of 2 cases. J Oral Maxillofac Surg 61:520-524

16. Fernández-Prieto A, García-Raya $\mathrm{P}$, Burgueño M, Muñoz-Caro J, Frutos R (2005) Endovascular treatment of pseudoaneurysm of the descending palatine artery after orthognathic surgery: technical note. Int J Oral Maxillofac Surg 34:321-323

17. Manafi A, Ghenaati H, Dezham F, Arshad M (2007) Massive repeated nose bleeding after bimaxillary osteotomy. J Craniofac Surg 18:1491-4193

18. Elton VJ, Turnbull IW, Foster ME (2007) An overview of the management of pseudoaneurysm of the maxillary artery: a report of a case following mandibular subcondylar osteotomy. J Craniomaxillofac Surg 35:52-56

19. Chepla KJ, Totonchi A, Hsu DP, Gosain AK (2010) Maxillary artery pseudoaneurysm after Le Fort I osteotomy: treatment using transcatheter arterial embolization. J Craniofac Surg 21:1079-1081

20. Lai JP, Hsieh CH, Chen YR, Liang CC (2005) Unusual late vascular complications of sagittal split osteotomy of the mandibular ramus. J Craniofac Surg 16:664-668

21. Kennedy JW, Kent JN (1970) False aneurysm and a partial facial paralysis secondary to mandibular fracture: report of case. J Oral Surg 28:854-856

22. Tarkan O, Sürmelioğlu O, Tuncer U, Akgül E (2010) Face skin necrosis following embolization for arteriovenous malformations: a case report. Oral Maxillofac Surg 14:49-52

23. Tseng EY, Narducci CA, Willing SJ (1998) Angiographic embolization for epistaxis: a review of 114 cases. Laryngoscope 108:615-619

24. Pagès ON, Alicchio F, Keren B, Diallo S, Lefebvre F, Valla JS, Poli-Merol ML (2008) Management of brachial artery aneurisms in infants. Pediatr Surg Int 24:509-513 